\title{
Anaesthesia of pregnant women
}

\author{
Zaneta Jastrzeloska-Stojko ${ }^{1}$, Marcin Sadlocha² ${ }^{\circledR}$ \\ ${ }^{1}$ Department of Anaesthesiology, University Clinical Center, Medical University of Silesia in Katowice, Poland \\ ${ }^{2}$ Clinic of Gynecology, Obstetrics and Gynecological Oncology, Department of Health Science in Katowice, \\ Medical University of Silesia, Katowice, Poland
}

\begin{abstract}
Labor pain is not only an unpleasant mental experience, but one of the most important factors that may negatively affect the course of labor and the well-being of the fetus. Over the years, many techniques for relieving labor pain have been developed, ranging from non-pharmacological (acupuncture, TENS, hypnosis...), through opioids and aeriform anesthetics, to regional analgesia techniques. Numerous studies and meta-analyzes prove that central blockades are the gold standard of labor analgesia and debunk the myths that these blockages are negatively limited to the course of labor. In the light of recent studies, the claim that epidural analgesia increases the risk of termination by caesarean section should be rejected. It has also been proven that central blockades do not lower the child's APGAR score. Feeling, an indication to use a central block during labor, should be a subjective intolerance to pain and the wishes of the mother in labor. The review presents the directions of development and the current state of knowledge of modern medicine regarding various anesthesia techniques, their safety for the mother, fetus and newborn, as well as practical tips to increase the satisfaction of the mother in labor. Key words: partus; vaginal birth; anaesthesia; epidural analgesia
\end{abstract}

Ginekologia Polska 2021; 92, 10: 735-740

\section{INTRODUCTION}

Anaesthesia of a pregnant woman, regardless of the duration of pregnancy, is always a great challenge for the anaesthesiologist and requires close multidisciplinary cooperation. It is associated with a measurable risk to the mother and the fetus arising from the applied procedure. Qualified personnel and specialized equipment, as well as the ability to perform various types of anesthesia and fluent knowledge of the effects of the drugs used allow to predict and effectively prevent possible complications. The review presents the directions of development and the current state of knowledge of modern medicine regarding various anaesthesia techniques, their safety for the mother, fetus and newborn, as well as practical tips to increase the satisfaction of the mother in labor.

\section{QUALIFICATION FOR THE ANESTHESIA}

The location of the pathology requiring surgical treatment of the pregnant woman determines the choice of the possible anesthesia technique. The anaesthesiologic consultation should be performed earlier and allows a detailed explanation of the procedures, optimization of the general condition, commissioning the necessary specialist consultations and additional laboratory or imaging tests. The proposed techniques of anaesthesia should be selected taking into account the indications and contraindications and should be as safe as possible for the mother and the fetus.

\section{ANAESTHETIC DRUGS}

The effects of drugs on rapidly dividing cells in the first trimester of pregnancy may be teratogenic and lead to severe disorders of organogenesis, including severe congenital abnormalities of the fetus, including pregnancy loss. We do not have randomized trials assessing the teratogenic effects of anaesthetic drugs on the fetus, but it seems that the doses of routinely used anaesthetic drugs for various anaesthetic techniques are safe. This is confirmed by the analysis of the material collected in the National Study of the Prevention of Birth Defects in the United States, which showed that general or regional anaesthesia to pregnant women for dermatological, dental or gynaecological procedures, mainly in the cervical area, regardless of the duration of pregnancy, was not associated with the occurrence of 25 analyzed congenital malformations assessed in the study [1].

The hypnotic drugs used for the induction of general anaesthesia include thiopental, propofol, etomidate and ket- 
amine. Propofol and thiopental cause comparable haemodynamic changes in the mother, and the Apgar assessment of the newborn does not differ significantly depending on which of them was used [2]. Unlike ketamine, after which a significantly higher number of newborns are born with a lower Apgar result at one and five minutes when used for general anesthesia, compared to thiopental [3].

Used intravenously as a co-analgesic for caesarean section under spinal anaesthesia, it enhances the effect of local anaesthesia drugs, significantly extends the time of effective postoperative analgesia without significant adverse effects for the mother, typical for opioids [4].

Opioid drugs used in obstetrics for general anaesthesia or central blockers are fentanyl, remifentanil, sufentanil and morphine. They easily overcome the placental barrier, may cause respiratory depression in the fetus and affect the Apgar score in the newborn, but it seems that this difference compared to non-opioid analgesia is not clinically significant [5]. Remifentanil is a short-acting opioid for induction and maintenance of anaesthesia and is administered as a continuous infusion. It can cause short-term respiratory depression in the newborn requiring tactile stimulation, and even short-term mask ventilation, while it provides the mother with excellent hemodynamic stability and may reduce recovery during cesarean section [6].

Dexmedetomidine at a dose of $5 \mu \mathrm{g}$ administered subarachnoid together with bupivacaine for caesarean section enhances the anesthetic effect of bupivacaine, prolongs the duration of sensory blockade and analgesia, and reduces the need for other analgesics [7]. Lipophilic opioids are used as adjuvants in central blockades. Fentanyl at a dose of $25 \mu \mathrm{g}$ and sufentanil at a dose of $5 \mu \mathrm{g}$ in combination with hyperbaric bupivacaine used for spinal anesthesia of caesarean section are characterized by comparable effectiveness, they are safe for the mother and the fetus, while the analgesic effect of sufentanil lasts longer [8]. Sufentanil has no negative effects on the fetus due to its binding to alpha1-glycoprotein at doses below $30 \mu \mathrm{g}$.

\section{ANAESTHESIA FOR THE NATURAL DELIVERY}

Commonly used techniques of natural birth anaesthesia include central blockades - epidural analgesia (EA), combined spinal - epidural analgesia CSE, its variant (dural puncture epidural analgesia DPE) and continuous subarachnoid anaesthesia (CSA). An alternative to them is intravenous analgesia with remifentanil. The techniques listed above are combined with patient-controlled analgesia PCA [9].

\section{CENTRAL BLOCKADES}

All central blocks used to conduct continuous analgesia of natural labor involve the necessity of placing the catheter in the appropriate space of the spine. EA, CSE and DPE begin with the location of the epidural space most often using a Tuohy needle with the resistance drop method. Depending on the technique chosen, a thinner 25-27 G subarachnoid needle is inserted through the epidural needle and the dura mater is punctured, reaching the subarachnoid space, where a local anesthetic drug (CSE) is administered [9], or after puncturing the dura, the needle is extended without administration of the drug, leaving a hole (DPE) in it [10]. Finally, in all the above-mentioned techniques, a catheter is inserted into the epidural space through a Tuohy needle for continuous analgesia. Early catheter placement is particularly important in the case of possible complications throughout the course of labor on the part of pregnant woman (severe obesity, twin pregnancy, pre-eclampsia), or the anaesthesiologist expects difficulties in securing the respiratory tract of the woman [11].

In the DPE technique, the opening left in the dura allows the local anaesthetic drug to translocate freely into the subarachnoid space; Compared to epidural anaesthesia, it has a stronger effect on the roots of the sacral nerves and unilateral block develops less frequently. The fastest analgesic effect, on average after two to five minutes, is achieved with CSE, while the same level of anesthesia is achieved only after 15-20 minutes with EA. All the techniques may extend the duration of labor, increase the risk of instrumental extraction of the fetus, epidural hematoma or urinary retention [12].

Local anesthetic drugs that are particularly useful in obstetrics include bupivacaine, levobupivacaine, and ropivacaine. Ropivacaine in minimally levels overcomes the placental barrier, gives a sensory blockade comparable to bupivacaine, and less motor blockade, and it is less toxic to the cardiovascular and central nervous systems [13]. Sufentanil added to a local anesthetic in CSA accelerates the onset of sensory blockade, extends its duration and enhances the analgesic effect of local anaesthetics, a lower negative hemodynamic effect is observed, and achieves effective analgesia with maintained mobility and negligible toxicity to the fetus, however, to reduce uterine contractile activity and extend the duration of labor [14].

Epidural anaesthesia of natural labor is performed continuously - (continuous epidural infusion CEI) or intermittently, performed by an anaesthesiologist administering single boluses of a specific volume of the drug mixture, at specified intervals or automatically - using a programmed intermittent epidural pump (programmed intermittent epidural bolus PIEB). Studies show that continuous epidural with low basal flow combined with patient-controlled analgesia for PCEA for breakthrough pain relief increases medication use and more frequently requires an additional analgesic bolus, while high basal infusion reduces the incidence of breakthrough pain but increases motor block and, 
consequently, the need for instrumental extraction of the fetus and the risk of shoulder dystocia [15].

According to Wong, the onset of natural labor using CEI may differ depending on the anaesthesia technique used - EA or CSE, as well as the moment at which analgesia begins (first or second stage of labor). EA regardless of the stage of labor is started with a bolus of $5-15 \mathrm{~mL}$ of a mixture of $0.0625-0.125 \%$ bupivacaine with fentanyl $1-2 \mu \mathrm{g} / \mathrm{mL}$ (50-100 $\mu \mathrm{g})$ or with sufentanil $0.2-0.3 \mu \mathrm{g} / \mathrm{mL}(5-10 \mu \mathrm{g})$, and CSE, if it begins in the first stage of labor, an opioid is effective in minimizing pain - e.g., $25 \mu \mathrm{g}$ subarachnoid fentanyl, while a mixture of bupivacaine 1.25 is more effective if it begins in the late first or second stage of labor $-2.5 \mathrm{mg}$ with $15 \mu \mathrm{g}$ fentanyl administered subarachnoid. The maintenance of CEI in the above scheme is achieved using a constant infusion of bupivacaine $0.05-0.1 \%$ with fentanyl $1-2 \mu \mathrm{g} / \mathrm{mL}$ or sufentanil $0.2-0.3 \mu \mathrm{g} / \mathrm{mL}$ at a rate of $8-15 \mathrm{~mL} / \mathrm{h}$ [16]. If PCEA is added to the CEl, the scheme may be as follows: basic infusion of a mixture of $0.05-0.1 \%$ bupivacaine with $1.5-3 \mu \mathrm{g} / \mathrm{mL}$ fentanyl or $0.20-0.33 \mu \mathrm{g} / \mathrm{mL}$ sufentanil at a rate of $5-8 \mathrm{~mL} / \mathrm{h}$; PCEA bolus $5-10 \mathrm{~mL}$, withdrawal period 10-20 minutes [17].

PIEB of the first stage of natural labor with bupivacaine: after the test dose $(3 \mathrm{~mL} 0.125 \%$ bupivacaine with $3.3 \mu \mathrm{g} / \mathrm{mL}$ fentanyl) with an interval of three minutes. administration of $6 \mathrm{~mL}$ of a mixture of $0.125 \%$ bupivacaine with $3.3 \mu \mathrm{g} / \mathrm{mL}$ fentanyl twice to obtain a full loading dose. Anaesthesia maintenance: mixture of $0.0625 \%$ bupivacaine with $2 \mu \mathrm{g} / \mathrm{mL}$ fentanyl, bolus $10-12 \mathrm{~mL} / \mathrm{h}$, the first one hour after the loading dose and each subsequent one after 40 minutes, PCEA bolus of the same $5 \mathrm{~mL}$ mixture, withdrawal period 10 minutes. up to a maximum dose of $30 \mathrm{~mL} / \mathrm{h}$ [18].

The most effective analgesic effect is achieved if the intervals between consecutive boluses do not exceed $40 \mathrm{~min}$ utes. Using higher concentrations of bupivacaine during first-stage analgesia bupivacaine $0.125 \%$ with $2 \mu \mathrm{g} / \mathrm{mL}$ fentanyl, a bolus volume of $5 \mathrm{~mL}$ provides effective analgesia if the bolus interval is 35 minutes; however, more often there is a sensory blockage exceeding the Th6 level [19].

PIEB of the first stage of natural labor with ropivacaine: after the test dose ( $3 \mathrm{~mL} 1.73 \%$ Lidocaine carbonate), administration of the full loading dose of a mixture of $0.08 \%$ ropivacaine with $0.3 \mu \mathrm{g} / \mathrm{mL}$ of sufenanil in the amount of $10 \mathrm{~mL}$, maintenance of anaesthesia: $10 \mathrm{~mL}$ bolus of the mixture, the first hour after the loading dose and each subsequent PCEA bolus of the same mixture every 42 minutes - the first $10 \mathrm{~mL}$, the next $5 \mathrm{~mL}$, withdrawal period 10 minutes. Such a scheme allows to avoid motor blockade and hypotension; however, it requires further studies to assess its effectiveness throughout the delivery [20].

Comparison of the effectiveness of analgesic therapy and the severity of side effects of anaesthesia of natural labor using CEI + PCEA vs PIEB + PCEA show that PIEB has an advantage over the continuous technique, provides comparable analgesia with lower drug consumption, gives greater satisfaction to the mother and a lower risk of side effects in the form of hypotension or motor block resulting in the necessity of instrumental extraction of the fetus [21].

Advantage of PIEB + PCEA ( $0.1 \%$ ropivacaine $+2 \mu \mathrm{g} / \mathrm{mL}$ fentanyl, 5-10 mL bolus every 1 hour, PCEA $5 \mathrm{~mL}$ bolus, withdrawal period $10 \mathrm{~min}$.), Compared to $\mathrm{CEl}$ (0.2\% ropivacaine $+2 \mu \mathrm{g} / \mathrm{mL} / \mathrm{mL}$ fentanyl, infusion $5-15 \mathrm{~mL} / \mathrm{h}$ ) has also been shown during second-stage anesthesia, indicating that the intermittent method is associated with a lower risk of motor blockade, a shorter second stage of labor in primiparous women, without affecting its duration in multiparous women and a reduction in the total dose ropivacaine [22].

\section{Continuous spinal anaesthesia}

Continuous spinal anaesthesia (CSA) is relatively rarely used in obstetrics due to the high rate of post-dural headaches and difficulties in placing the catheter in the desired location in the subarachnoid space. Compared to CEI or single subarachnoid single-shot spinal anesthesia (SSA), it is characterized by the possibility of obtaining a precisely defined amount of sensory blockade tailored to the needs, using small, titrated doses of drugs, which allows better control of hemodynamic changes following sympathetic blockade [23]. With the use of CSA, it is possible to perform both natural delivery and caesarean section [24]. Labor analysis is performed using a mixture of $0.1 \%$ ropivacaine with $2 \mu \mathrm{g} / \mathrm{mL}$ fentanyl or $0.0625 \%$ bupivacaine with $2 \mu \mathrm{g} / \mathrm{mL}$ fentanyl by continuous infusion at a rate of $2 \mathrm{~mL} / \mathrm{h}$; Breakthrough pains require a bolus of $2 \mathrm{~mL}$ of the used mixture at an interval of at least 15 minutes, provided that the maximum number of additional doses does not exceed 3 per hour [25]. Remember to increase the starting dose by the dead space volume of the catheter used. A catheter inserted into the subarachnoid space can be used for caesarean section. The starting dose is $5-7.5 \mathrm{mg}$ of $0.5 \%$ isobaric bupivacaine or $0.75 \%$ of hyperbaric bupivacaine; subsequent doses of $2.5 \mathrm{mg}$ of the agent used should be added every three to five minutes in order to obtain the desired level of anaesthesia [25].

\section{Intravenous analgesis}

Intravenous analgesia is an alternative method of relieving labor pain to central blockades. It is carried out with the use of intramuscular or intravenous opiates, most often in the form of patient-controlled analgesia (PCA). Remifentanil (PCA-R) - a short-acting opioid with a metabolism independent of the liver and kidneys - has turned out to be particularly useful recently. Provides quick analgesia with high satisfaction of the giving birth compared to other opioids, the comparison with EA or CSE is lower in this 
analysis; in addition, PCA-R increases the risk of maternal apnea, desaturation, nausea, vomiting and sedation, without reducing the Apgar score below seven in the fifth minute in neonates compared to EA, and the risk of cesarean delivery is comparable to EA/CSE [26]. In the RESPITE study, the object was to compare the effectiveness of the analgesic effect of PCA-R (40 ug bolus on demand, 2 min. blockade) with intramuscular pethidine (100 mg every 4 hours, up to $400 \mathrm{mg} / \mathrm{d}$ ) during labor, showed that PCA-R reduces by half the necessity to perform additional $A E$ in order to satisfactorily eliminate the pain enabling the termination of natural labor. Good clinical practice of labor anesthesia with the use of opioid PCA requires constant monitoring of the saturation of arterial blood in the pregnant woman, assessment of the degree of sedation and pain using dedicated scales, blood pressure measurement, one-to-one care and CTG monitoring [27].

New randomized trials comparing PCA- $\mathrm{R}$ with PIEB confirm that PCA-R is a safe alternative for the mother, fetus and newborn, and has low side effects in the form of sedation, nausea and vomiting. Even in some respects, some researchers have recognized an advantage of PCA-R over epidural techniques, especially in terms of shortening the duration of the first stage of labor or a higher spontaneous delivery rate without adversely affecting the mother or the newborn [28].

\section{Inhalation analgesia of labor}

Inhalation analgesia of labor is often described as archaic, it is based on the use of a mixture of nitrous oxide with oxygen in the ratio 1:1 — Entonox. Nitrous oxide thanks to its short half-life - less than three minutes and low blood solubility. It is absolutely safe for the child and mother during delivery [29]. Intermittent use of LIVOPAN to relieve labor pain until the end of the second stage of labor, compared to inhalation of pure oxygen, brings significant relief to the mother, reduces the need for intravenous pethidine $0.5 \mathrm{mg} / \mathrm{kg}$ and increases maternal satisfaction and is safe for the fetus [30]. The main advantages of $\mathrm{N} 2 \mathrm{O}$ as an analgesic during labor are its favorable pharmacological profile (quick onset and rapid rinse out 30-50 s) and the possibility of inhalation by the patient herself, who controls its administration [31].

\section{ANAESTHESIA FOR CESAREAN SECTION}

The lack of vaginal labor progress, fatigue of the woman in labor despite pharmacotherapy, ineffective obstetric maneuvers to induce uterine contractions, and deteriorating fetal well-being, mainly due to impending asphyxia, are associated with the need to terminate delivery by caesarean section. The obstetrician decides about the conversion to cesarean section. Depending on the circumstances, the presence or absence of urgent obstetric indications for termination of pregnancy, as well as the skills and experience of the anesthesiologist and equipment, we can choose from EA, CSE, DPE, CSA, SSA or general anesthesia. Central locks are preferred. When deciding to perform EA for Caesarean section, which has a negligible impact on the mother and the fetus, one should consider a delayed onset of action compared to CSE (18.3 vs 9.7 minutes), as well as the risk of incomplete sensorimotor blockade and insufficient muscle relaxation [32]. Sufentanl in a dose of $15-20 \mu \mathrm{g}$ as an adjuvant added to $0.65 \%$ ropivacaine in EA is effective in relieving intraoperative somatic-visceral pain during strong traction of abdominal organs during caesarean section performed in multiparous women with uterine scar following previous cesarean sections; the use of higher doses of sufentanil increases the risk of side effects associated with the opioid (nausea, vomiting, hypotension). In the aforementioned group of women, an effective supplementation of EA is PCA-R in a dose of $0.025-0.05 \mu \mathrm{g} / \mathrm{kg} / \mathrm{min}$, the use of which guarantees sedation and significantly improves the satisfaction of the mother in labor [33].

The great popularity of CSE is due to the possibility of continuing analgesic treatment after cesarean section by the epidural price list. For spinal anesthesia, hyperbaric $0.5-0.75 \%$ bupivacaine in a dose of $7.5-12.5 \mathrm{mg}$ is used in combination with an opioid (fentanyl, sufentanil, morphine) - fentanyl 10-20 $\mu \mathrm{g}$, sufentanil $5 \mu \mathrm{g}$, morphine $0.2-0.3 \mathrm{mg}$. Previous suggestions that low doses of bupivacaine $(<8 \mathrm{mg})$ used during spinal anesthesia causes lower pressure drops and other side effects have not been confirmed because the quality of this anaesthesia is insufficient and requires additional painkillers [34].

Hypotension following anaesthesia is a serious problem concerning central blockades, especially SSA. Severe or persistent hypotension contributes to maternal dizziness, nausea and vomiting. Ephedrin, phenylephrine and norepinephrine are sympathomimetics of alpha receptors, their action guarantees an increase in blood pressure. They act on beta receptors to a different extent, ephedrin the strongest - it causes tachycardia in the mother and increases the demand for oxygen [35]. It easily crosses the placental barrier, increases fetal metabolism and may contribute to fetal acidosis. Phenylephrin is almost beta-negative and therefore causes reflex bradycardia that lasts 20 minutes after IV and 50 minutes after administration of SC Norepinephrine is also an almost selective agonist of alpha receptors, it poorly penetrates the placenta, it works for about 60 seconds, thanks to which it is easily controllable during administration. Used to treat hypotension during SSA for cesarean delivery (infusion of $4 \mathrm{ug} / \mathrm{min} \mathrm{NA}$, beginning at $2.5-2.7 \mathrm{~mL} 0.6 \%$ subarachnoid hyperbaric ropivacaine) reduces the risk of maternal tachycardia and provides greater hemodynamic stability compared to with ephedrine infusion $4 \mathrm{mg} / \mathrm{min}$. [36]. Nor- 
epinephrine provides better hemodynamic stability and is less likely to cause bradycardia compared to phenylephrine.

\section{GENERAL ANESTHESIA}

General anesthesia of a pregnant woman for each procedure, including caesarean section, is the least frequently chosen option. The most common reasons are immediate or urgent indications for surgery, lack of time to perform a central block or insufficient scope of anaesthesia obtained thanks to regional anaesthesia [11]. Coagulation disorders, intracranial hypertension, systemic infection or infection in the puncture area in a pregnant woman make it impossible to perform a central block, while vaginal bleeding or eclampsia force the obstetrician to decide on immediate termination of pregnancy. Close cooperation between an anaesthesiologist and an obstetrician gynecologist is required. Apart from the constant assessment of the pregnant woman's vital functions in the perioperative period, the fetal heart rate and uterine contractions should be monitored.

From $12 \mathrm{Hbd}$, a pregnant woman should always be treated as a person with a "full stomach" regardless of the time of eating the last meal - obligatory for 30 minutes. prior to anesthesia, antacids should be administered, and administration of a histamine $\mathrm{H} 2$ receptor antagonist should be considered [11]. The pregnant patient should be properly positioned - with rotation to the left side, in the anti-trend position (prophylaxis of the inferior vena cava syndrome and strengthening of the lower esophageal sphincter). Induction of general anesthesia must be rapid and fluent [rapid-sequence intubation (RSI)] due to the risk of aspiration of food content, reliable 3-5 minutes pre-oxygenation (avoiding apnea due to very low respiratory reserve - hypoxia and hypercapnia during induction of anesthesia causes acidosis in fetus), with oxygen flow above $10 \mathrm{l} / \mathrm{min}$. through a fully sealed mask with capnographic monitoring [37]. Common practice in obstetric patients should be the use of propofol and rocuronium $(1.2 \mathrm{mg} / \mathrm{kg}$ ) with access to sugammadex, succinylcholine $(1.5-2 \mathrm{mg} / \mathrm{kg})$ is also acceptable, unless there are contraindications; Tracheal intubation remains the gold standard, and both propofol and sevoflurane are suitable for the maintenance of anesthesia. N2O is also a good option or addition to an inhalation anesthetic. All halogenated inhalation anesthetics in equivalent concentrations produce a comparable dose-dependent reduction in uterine contraction and a reduction in resting tone. This effect disappears quickly after their supply in the breathing mixture is discontinued. Used in high flow rates, they can lead to uterine atony and life-threatening hemorrhage immediately after delivery.

\section{CONCLUSIONS}

The paper presents the latest achievements in modern medicine concerning the pathways of anesthetic man- agement with a pregnant woman requiring anesthesia. The safety and health of the mother, fetus and newborn baby are of paramount importance to the medical and nursing team that takes care of them, carries out diagnostic procedures or performs complex operating procedures.

\section{Funding}

This review received no external funding.

\section{Acknowledgments}

The Cohrane and PubMed database was used.

\section{Conflicts of interest}

The authors declare no conflict of interest.

\section{REFERENCES}

1. Fisher SC, Siag K, Howley MM, et al. National Birth Defects Prevention Study. Maternal surgery and anesthesia during pregnancy and risk of birth defects in the National Birth Defects Prevention Study, 1997-2011. Birth Defects Res. 2020; 112(2): 162-174, doi: 10.1002/bdr2.1616, indexed in Pubmed: 31840947.

2. Tumukunde J, Lomangisi DD, Davidson O, et al. Effects of propofol versus thiopental on Apgar scores in newborns and peri-operative outcomes of women undergoing emergency cesarean section: a randomized clinical trial. BMC Anesthesiol. 2015; 15: 63, doi: 10.1186/s12871-015-0044-6, indexed in Pubmed: 25924776.

3. Houthoff KhemLani K, Weibel S, Kranke P, et al. Hypnotic agents for induction of general anesthesia in cesarean section patients: A systematic review and meta-analysis of randomized controlled trials. J Clin Anesth. 2018; 48: 73-80, doi: 10.1016/j.jclinane.2018.04.010, indexed in Pubmed: 29778972.

4. Heesen M, Böhmer J, Brinck ECV, et al. Intravenous ketamine during spinal and general anaesthesia for caesarean section: systematic review and meta-analysis. Acta Anaesthesiol Scand. 2015; 59(4): 414-426, doi: 10.1111/aas.12468, indexed in Pubmed: 25789942.

5. White LD, Hodsdon A, An GH, et al. Induction opioids for caesarean section under general anaesthesia: a systematic review and meta-analysis of randomised controlled trials. Int J Obstet Anesth. 2019; 40: 4-13, doi: 10.1016/j.ijoa.2019.04.007, indexed in Pubmed: 31230994.

6. Devroe S, Van de Velde M, Rex S. General anesthesia for caesarean section. Curr Opin Anaesthesiol. 2015; 28(3): 240-246, doi: 10.1097/ACO.0000000000000185, indexed in Pubmed: 25827280.

7. Xia F, Chang X, Zhang Y, et al. The effect of intrathecal dexmedetomidine on the dose requirement of hyperbaric bupivacaine in spinal anaesthesia for caesarean section: a prospective, double-blinded, randomized study. BMC Anesthesiol. 2018; 18(1): 74, doi: 10.1186/s12871-018-0528-2, indexed in Pubmed: 29935528.

8. Braga Ad, Braga FS, Hirata ES, et al. Association of lipophilic opioids and hyperbaric bupivacaine in spinal anesthesia for elective cesarean section. Randomized controlled study. Acta Cir Bras. 2014; 29(11): 752-758, doi: 10.1590/s0102-86502014001800010, indexed in Pubmed: 25424297.

9. Lim G, Facco FL, Nathan N, et al. A Review of the Impact of Obstetric Anesthesia on Maternal and Neonatal Outcomes. Anesthesiology. 2018; 129(1): 192-215, doi: 10.1097/ALN.0000000000002182, indexed in Pubmed: 29561267.

10. Chau A, Bibbo C, Huang CC, et al. Dural Puncture Epidural Technique Improves Labor Analgesia Quality With Fewer Side Effects Compared With Epidural and Combined Spinal Epidural Techniques: A Randomized Clinical Trial. Anesth Analg. 2017; 124(2): 560-569, doi: 10.1213/ANE.0000000000001798, indexed in Pubmed: 28067707.

11. Practice Guidelines for Obstetric Anesthesia: An Updated Report by the American Society of Anesthesiologists Task Force on Obstetric Anesthesia and the Society for Obstetric Anesthesia and Perinatology. Anesthesiology. 2016; 124(2): 270-300.

12. Lieberman $E, O^{\prime}$ Donoghue $C$. Unintended effects of epidural analgesia during labor: A systematic review. Am J Obstet Gynecol. 2002; 186(5): S31-S68, doi: 10.1016/s0002-9378(02)70181-6. 
13. Leone S, Di Cianni S, Casati A, et al. Pharmacology, toxicology, and clinical use of new long acting local anesthetics, ropivacaine and levobupivacaine. Acta Biomed. 2008; 79(2): 92-105, indexed in Pubmed: 18788503.

14. Sultan P, Murphy $C$, Halpern $S$, et al. The effect of low concentrations versus high concentrations of local anesthetics for labour analgesia on obstetric and anesthetic outcomes: a meta-analysis. Can J Anaesth. 2013; 60(9): 840-854, doi: 10.1007/s12630-013-9981-z, indexed in Pubmed: 23925722

15. Onuoha OC. Epidural Analgesia for Labor: Continuous Infusion Versus Programmed Intermittent Bolus. Anesthesiol Clin. 2017; 35(1): 1-14, doi: 10.1016/j.anclin.2016.09.003, indexed in Pubmed: 28131113.

16. Wong CA. In: Chestnut DH. ed. Epidural and Spinal Analgesia/Anesthesia for Labor and Vaginal Delivery, Obstetric Anesthesia: Principles and Practice. Mosby 2014: 490.

17. Wong CA. Advances in labor analgesia. Int J Womens Health. 2010; 1: 139-154, doi: 10.2147/ijwh.s4553, indexed in Pubmed: 21072284.

18. Zakus P, Arzola C, Bittencourt R, et al. Determination of the Optimal Programmed Intermittent Epidural Bolus Volume of Bupivacaine $0.0625 \%$ With Fentanyl $2 \mu \mathrm{g} \cdot \mathrm{mL}-1$ at a Fixed Interval of Forty Minutes: A Biased Coin Up-And-Down Sequential Allocation Trial. Anaesthesia. 2018; 73(4): 459-465.

19. Bittencourt $R$, Arzola $C$, Zakus $P$, et al. A biased coin up-and-down sequential allocation trial to determine the optimum programmed intermittent epidural bolus time interval between $5 \mathrm{~mL}$ boluses of bupivacaine $0.125 \%$ with fentanyl $2 \mu \mathrm{g} \cdot \mathrm{mL}$. Can J Anaesth. 2019; 66(9): 1075-1081, doi: 10.1007/s12630-019-01407-7, indexed in Pubmed: 31152372.

20. Zhou SQ, Wang J, Du WJ, et al. Optimum interval time of programmed intermittent epidural bolus of ropivacaine $0.08 \%$ with sufentanyl $0.3 \mu \mathrm{g} / \mathrm{mL}$ for labor analgesia: a biased-coin up-and-down sequential allocation trial. Chin Med J (Engl). 2020; 133(5): 517-522, doi: 10.1097/CM9.0000000000000669, indexed in Pubmed: 32142491.

21. McKenzie CP, Cobb B, Riley ET, et al. Programmed intermittent epidural boluses for maintenance of labor analgesia: an impact study. Int J Obstet Anesth. 2016; 26: 32-38, doi: 10.1016/j.ijoa.2015.11.005, indexed in Pubmed: 26775896.

22. Bullingham $A$, Liang $S$, Edmonds $E$, et al. Continuous epidural infusion vs programmed intermittent epidural bolus for labour analgesia: a prospective, controlled, before-and-after cohort study of labour outcomes. $\mathrm{Br}$ J Anaesth. 2018; 121(2): 432-437, doi: 10.1016/j.bja.2018.03.038, indexed in Pubmed: 30032882.

23. Moore JM. Continuous spinal anesthesia. Am J Ther. 2009; 16(4): 289-294, doi: 10.1097/MJT.0b013e3181729d2a, indexed in Pubmed: 19546804.

24. Tao W, Grant EN, Craig MG, et al. Continuous Spinal Analgesia for Labor and Delivery: An Observational Study with a 23-Gauge Spinal Catheter. Anesth Analg. 2015; 121(5): 1290-1294, doi: 10.1213/ANE.0000000000000903, indexed in Pubmed: 26273746.
25. Veličković I, Pujic B, Baysinger CW, et al. Continuous Spinal Anesthesia for Obstetric Anesthesia and Analgesia. Front Med (Lausanne). 2017; 4: 133, doi: 10.3389/fmed.2017.00133, indexed in Pubmed: 28861414.

26. Beh ZY, Au Yong PS, Lye S, et al. Continuous spinal anaesthesia: A retrospective analysis of 318 cases. Indian J Anaesth. 2018; 62(10): 765-772, doi: 10.4103/ija.IJA 387 18, indexed in Pubmed: 30443059.

27. Weibel S, Jelting $Y$, Afshari A, et al. Patient-controlled analgesia with remifentanil versus alternative parenteral methods for pain management in labour. Cochrane Database Syst Rev. 2017; 4: CD011989, doi: 10.1002/14651858.CD011989.pub2, indexed in Pubmed: 28407220.

28. Van de Velde $M$, Carvalho B. Remifentanil for labor analgesia: an evidence-based narrative review. Int J Obstet Anesth. 2016; 25: 66-74, doi: 10.1016/j.ijoa.2015.12.004, indexed in Pubmed: 26777438.

29. Thorbiörnson A, da Silva Charvalho P, Gupta A, et al. Duration of labor delivery mode and maternal and neonatal morbidity after remifentanil patient-controlled analgesia compared with epidural analgesia. Eur J Obstet Gynecol Reprod Biol X. 2020; 6: 100106, doi: 10.1016/j. eurox.2019.100106, indexed in Pubmed: 32300757.

30. Nitrous oxide. 2018 Drugs and Lactation Database (LactMed) [Internet]. Bethesda (MD): National Library of Medicine (US) 2006

31. Attar AS, Feizabadi AS, Jarahi L, et al. Effect of Entonox on reducing the need for Pethidine and the Relevant Fetal and Maternal Complications for Painless Labor. Electron Physician. 2016; 8(12): 3325-3332, doi: 10.19082/3325, indexed in Pubmed: 28163844.

32. Buhre W, Disma N, Hendrickx J, et al. European Society of Anaesthesiology Task Force on Nitrous Oxide: a narrative review of its role in clinical practice. Br J Anaesth. 2019; 122(5): 587-604, doi: 10.1016/j. bja.2019.01.023, indexed in Pubmed: 30916011.

33. Choi DH, Kim JA, Chung IS. Comparison of combined spinal epidural anesthesia and epidural anesthesia for cesarean section. Acta Anaesthesiol Scand. 2000; 44(2): 214-219, doi: 10.1034/j.1399-6576.2000.44 0214.X, indexed in Pubmed: 10695917.

34. Wei $Y, Y u n X, Y u, Y$, et al. Continuous intravenous infusion of remifentanil improves the experience of parturient undergoing repeated cesarean section under epidural anesthesia, a prospective, randomized study. BMC Anesthesiol. 2019; 19: 243. BMC Anesthesiol. 2019; 19: 243.

35. Arzola C, Wieczorek PM. Efficacy of low-dose bupivacaine in spinal anaesthesia for Caesarean delivery: systematic review and meta-analysis. Br J Anaesth. 2011; 107(3): 308-318, doi: 10.1093/bja/aer200.

36. Cooper DW, Carpenter M, Mowbray P, et al. Fetal and maternal effects of phenylephrine and ephedrine during spinal anesthesia for cesarean delivery. Anesthesiology. 2002; 97(6): 1582-1590, doi: 10.1097/00000542200212000-00034, indexed in Pubmed: 12459688.

37. Xu S, Mao M, Zhang S, et al. A randomized double-blind study comparing prophylactic norepinephrine and ephedrine infusion for preventing maternal spinal hypotension during elective cesarean section under spinal anesthesia: A CONSORT-compliant article. Medicine (Baltimore). 2019; 98(51): e18311, doi: 10.1097/MD.0000000000018311, indexed in Pubmed: 31860981. 